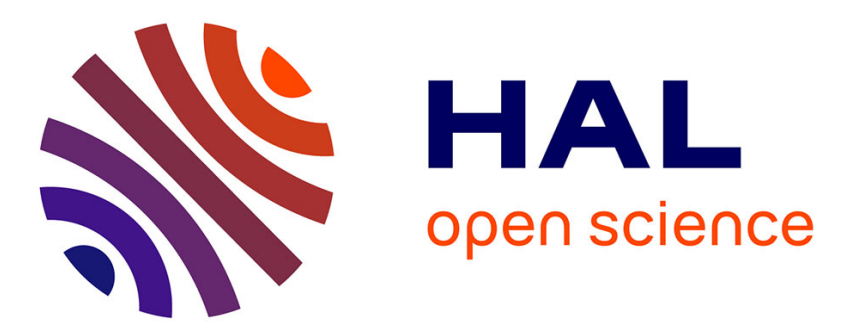

\title{
Long reach Quantum Dash based Transceivers using Dispersion induced by Passive Optical Filters
}

Siddharth Joshi, Luiz Anet Neto, Nicolas Chimot, Sophie Barbet, Mathilde Gay, Abderrahim Ramdane, François Lelarge

\section{- To cite this version:}

Siddharth Joshi, Luiz Anet Neto, Nicolas Chimot, Sophie Barbet, Mathilde Gay, et al.. Long reach Quantum Dash based Transceivers using Dispersion induced by Passive Optical Filters. 40th European Conference on Optical Communication (ECOC 2014), Sep 2014, Cannes, France. pp.P.7.11, 10.1109/ECOC.2014.6963988 . hal-01080808

\section{HAL Id: hal-01080808 https://hal.science/hal-01080808}

Submitted on 6 Nov 2014

HAL is a multi-disciplinary open access archive for the deposit and dissemination of scientific research documents, whether they are published or not. The documents may come from teaching and research institutions in France or abroad, or from public or private research centers.
L'archive ouverte pluridisciplinaire HAL, est destinée au dépôt et à la diffusion de documents scientifiques de niveau recherche, publiés ou non, émanant des établissements d'enseignement et de recherche français ou étrangers, des laboratoires publics ou privés. 


\title{
Long reach Quantum Dash based Transceivers using Dispersion induced by Passive Optical Filters
}

\author{
S. Joshi ${ }^{(1)}$, L. Anet. Neto ${ }^{(2)}$, N. Chimot ${ }^{(1)}$, S. Barbet ${ }^{(1)}$, M. Gay ${ }^{(2)}$, A. Ramdane ${ }^{(3)}$, François Lelarge ${ }^{(1)}$ \\ (1) III-V Lab, a joint Laboratory of "Alcatel Lucent Bell Labs", "Thales Research \&Technology" and \\ "CEA-LETI" Route de Nozay, 91460 Marcoussis, France. siddharth.joshi@3-5lab.fr \\ (2) CNRS-Foton Laboratory (UMR 6082), Enssat, CS 80518, 22305 Lannion, France \\ (3) Laboratoire de Photonique et de Nanostructures, CNRS, Marcoussis, France
}

\begin{abstract}
We investigate the small signal frequency response for a low chirp Quantum Dash directly modulated laser in combination with an off-the-shelf passive optical filter. We report the enhancement of channel-bandwidth and the eye reshaping using such a transmitter assembly that allows transmitting $10 \mathrm{Gbit} / \mathrm{s}$ signal from $0 \mathrm{~km}$ up to $100 \mathrm{~km}$ using constant bias conditions.
\end{abstract}

\section{Introduction}

Giga-bit bandwidth provisions are required today to address the growing demand for internet bandwidth in access networks. With the ongoing standardization of next generation passive optical networks (NGPON2), it is of paramount importance to develop innovative $10 \mathrm{Gbit} / \mathrm{s}$ transmitters at $1.55 \mu \mathrm{m}$ for long reach, low cost and high capacity access and metropolitan networks which could be deployed over the period of next few years.

Since Intensity Modulation and Direct Detection (IM-DD) is still maintained as a transmission approach for cost reasons, directly modulated lasers (DMLs) appear to be the most attractive candidates for access networks. DMLs are preferred owing to their high output power, low threshold current, tolerance to optical feedback, and ability to operate in semi-cooled or un-cooled conditions. However, for a conventional Quantum Well (QW) DML, the transmission distances are limited to the range of about $30 \mathrm{~km}^{1}$, because of frequency chirping at $1.55 \mu \mathrm{m}$ inherent to high bit rate IM-DD modulation. It also proved difficult to achieve high dynamic extinction ratios (DER). A low cost solution for $10 \mathrm{Gbits} / \mathrm{s}$ over distance of $40-100 \mathrm{~km}$ and high extinction ratio $(6-8 \mathrm{~dB})$ is therefore still required.

Self-assembled semiconductor quantum-dot (QDot) and quantum-dash (QDash) based lasers appear to be promising devices since higher differential gain and lower chirp are expected. Recently, p-doping of the Qdash active layers led to further improvement of intrinsic dynamic properties ${ }^{2,3}$ and Henry's factors as low as 2.5 have been reported. Unamplified $10 \mathrm{Gbit} / \mathrm{s}$ transmissions in standard single mode fibre from back-to-back up to $65 \mathrm{~km}$ at constant operating conditions was hence demonstrated ${ }^{4}$.

The combination of this promising material system with a commercially available etalon filter enables error-free $10 \mathrm{Gbit} / \mathrm{s}$ transmissions over a distance in excess of $100 \mathrm{~km}$ in standard single mode (SMF) fibre span. A constant bias current from back-to-back up to $100 \mathrm{~km}$ with DER greater than $6 \mathrm{~dB}$ was reported ${ }^{5}$.

In this paper we investigate in detail the combination of such a low chirp QDash based DML with a passive optical filter. An enhancement of the modulation bandwidth of the laser up to $5 \mathrm{GHz}$ is demonstrated. It is likely related to the negative chirp induced by the optical filter, as expected from the transfer function of the passive filter. The IM-DD channel frequency response is showing that the filter is required both for increasing the extinction ratio for long distances $(>40 \mathrm{~km})$ and for reshaping the eye for short distances $(<25 \mathrm{~km})$.

\section{Expected dispersion induced by the passive filter}

The intensity and phase of an optical field at filter output can be calculated by considering the transfer function $\mathcal{F}$ of the Etalon Filter as a function of wavelength $\lambda$, with a free spectral range (FSR), reflectivity $R$ and transitivity $T$

$$
\mathcal{F}=\frac{T}{1-R e^{i\left(\frac{2 \pi c}{F S R * \lambda}\right)}}
$$

The phase of the output light will be given by the phase of the complex transfer function as

$$
\varphi_{\mathcal{F}}=\tan ^{-1}\left(\frac{\mathfrak{I}(\mathcal{F})}{\mathfrak{R}(\mathcal{F})}\right)
$$

The dispersion profile of the filter as a function of wavelength is thus given by

$$
d_{\mathcal{F}}=-\frac{d}{d \lambda}\left(-\frac{\lambda^{2}}{2 \pi c} \frac{d \varphi}{d \lambda}\right)
$$

Thus, the output field is seen to be affected by the dispersion term produced by the filter in eq. 3. The dispersion profile of the filter is shown 




Fig.1: Dispersion profile of the filter

in Fig 1. The filter produces a positive dispersion for some wavelength and negative for the others, depending on the placement of the filter with respect to the laser wavelength. At the same time the filter is expected to damp the amplitude of the wavelength related to ' 0 ' bit.

\section{Impact of passive optical filter on modulation bandwidth of QDash lasers}

The small signal modulation response of a low chirp quantum dash laser is measured using a network analyzer with and without filter in back to back and after $25 \mathrm{~km}$ and $50 \mathrm{~km}$ (Fig.2). It is observed that the bandwidth of the laser is enhanced from $10 \mathrm{GHz}$ to around $15 \mathrm{GHz}$ in back to back upon utilizing the filter in the channel as shown in Fig 2a. We hence observe a peaking behaviour of the modulation response, in good agreement with the analysis performed by Wang et $\mathrm{al}^{6}$ and Anet-Neto et $\mathrm{al}^{7}$. This is likely due to the negative dispersion coefficient introduced by the filter into the channel. The passive filter also modifies the chirp parameter of the laser and the signal at the output has a different value of chirp as compared to the laser.

The modulation response is then measured after $25 \mathrm{~km}$ propagation, again with and without the filter (Fig.2b). With no filter, the dispersion introduced by the fibre produces a dip in the

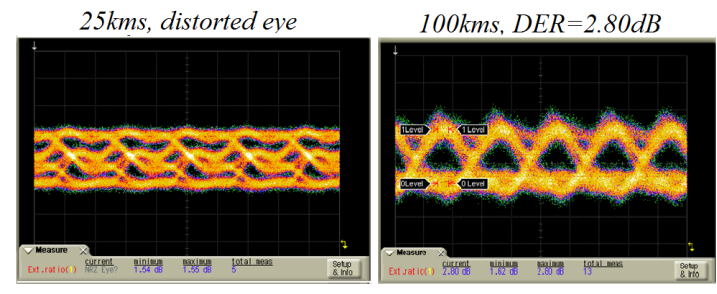

Fig.3: Eye Diagram with $25 \mathrm{kms}$ and $100 \mathrm{kms}$ of fibre, without filter.

channel bandwidth. A flat channel response is recovered upon introduction of the filter as a result of negative dispersion and positive chirp co-efficient, thus retrieving a flat channel response as shown in Fig.2(b), similar result is observed for a fibre length of $50 \mathrm{~km}$ Fig.2(c).

\section{Eye re-shaping effect as a function of transmission distance}

The effect of dispersion can further be observed in the eye diagrams of the transmitted $10 \mathrm{Gbit} / \mathrm{s}$ signals as shown in Fig. 3. For this, a standard $10 \mathrm{Gbit} / \mathrm{s}$ non return-to-zero (NRZ) laser modulation is realized with a pseudorandom binary sequence (PRBS) generator emitting $2^{31}$. 1 long words. Power launched into the fibre is maintained to $+3 \mathrm{dBm}$. The transmitted NRZ signal is sent to an Avalanche Photodiode (APD) receiver before error detection and measurement of eye patterns. We notice that the eye diagram at $25 \mathrm{~km}$ displays a distorted eye as shown in Fig. 3 when no filter is used in the transmission channel. This is due to the dip of the channel transfer function that limits the channel bandwidth of the signal that can be transmitted through the channel. The dip position, marked with the arrow in the typical IMDD channel response with $25 \mathrm{~km}$ of standard SMF shown in Fig.4, depends on the fibre distance whereas its depth is damped when one increases the chirp, for instance by increasing the injection current.

This dip shifts towards lower frequencies with higher values of accumulated dispersion in the link, i.e when longer length of fibre is added to
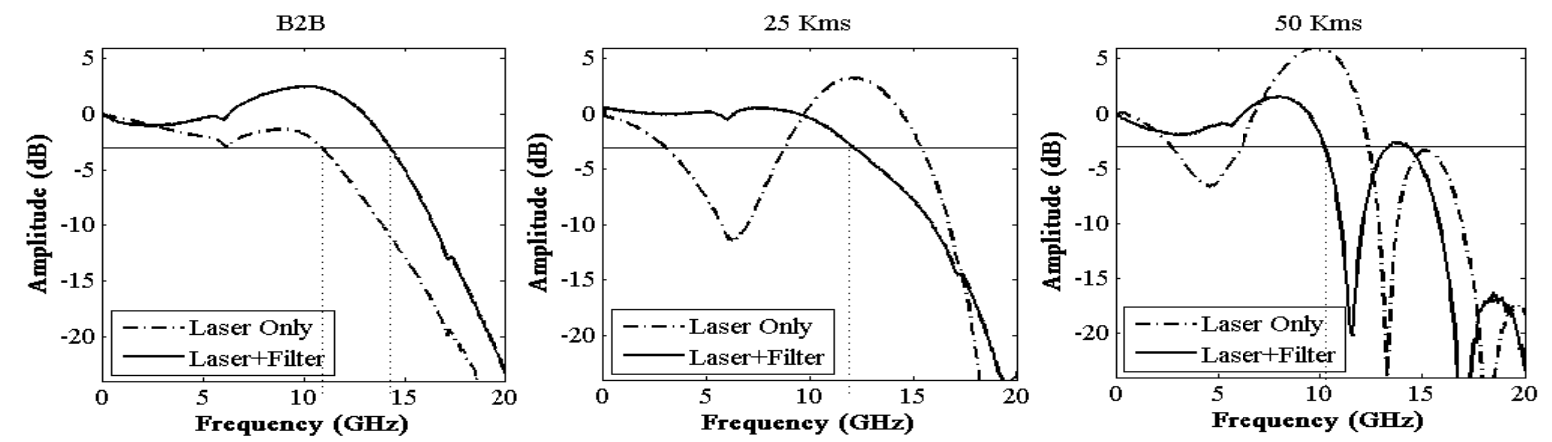

Fig. 2: Small Signal Modulation response with $25 \mathrm{~km}$ and $50 \mathrm{~km}$ of standard SMF with (solid line) and without filter (dashed lines) 


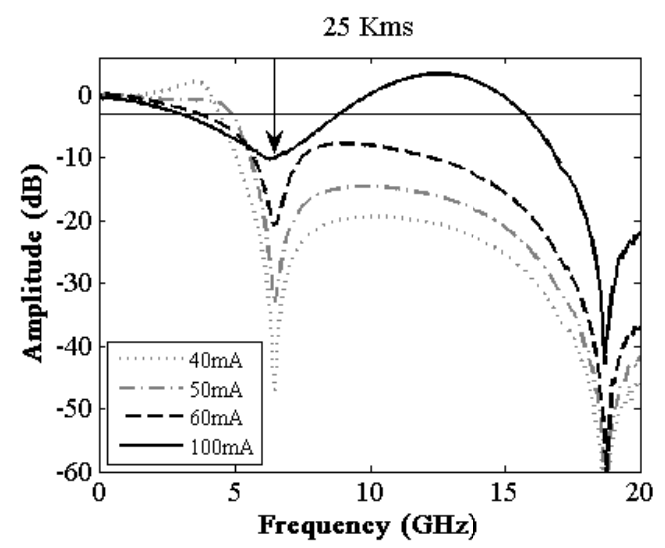

Fig.4: Small signal modulation response of Qdash DML with $25 \mathrm{Kms}$ fibre in channel.

the channel. As a consequence, the eye diagram is clearly open for long distance (50$100 \mathrm{~km}$ ) but fully distorted for short distances.

The measurement for eye diagram when repeated with conventional etalon filter added before the fibre span leads to a re-shaped and opened eye diagram (Fig. 5). This is consistent with the modulation response shown in Fig. $2 \mathrm{~b}$. Indeed, the use of the optical filter fills the dip for short distances.

In addition, the extinction ratio is increased as a


Fig.5: Eye Diagram with $25 \mathrm{~km}$ and $100 \mathrm{~km}$ of fibre, with filter and corresponding Bit Error curves from 0 to $100 \mathrm{kms}$. consequence of suppression of wavelength related to ' 0 ' bits. The extinction ratio is thus measured to be $6 \mathrm{~dB}$ from back to back and up to $100 \mathrm{~km}$ with a penalty free transmission, as shown in Fig. 5.

\section{Conclusions}

A Quantum Dash based DML combined with a commercial etalon filter is studied in details. We observe a peaking behaviour in the small signal response of the directly modulated laser, in good agreement with a negative dispersion that is expected to be induced by the optical filter.

The IM-DD channel frequency response provides an evidence that the filter is also reshaping the eye for short distances $(<25 \mathrm{~km})$ by damping the dip that occurs in the modulation response. Dynamic extinction ratio up to $8 \mathrm{~dB}$ and $6 \mathrm{~dB}$ for $10 \mathrm{GBit} / \mathrm{s}$ transmission over $65 \mathrm{~km}$ and $100 \mathrm{~km}$, respectively, are demonstrated.

Such low chirp QDash based DML combined with a commercially available etalon filter leads to floor free $10 \mathrm{~Gb} / \mathrm{s}$ transmission at constant bias from 0 to $100 \mathrm{~km}$ and therefore prove to be adequately adapted for access networks.

\section{Acknowledgements}

This work has been realized under the framework of EC-FP7 PPROPHET-ITN project and French ANR project DIQDOT.

\section{References}

[1] S. Mohrdiek et al,"10-Gb/s standard fibre transmission using directly modulated $1.55-\mu \mathrm{m}$ quantum-well DFB lasers," Phot. Tech. Lett., vol.7, no.11 (1995)

[2] Hein, S. et al, "The impact of p-doping on the static and dynamic properties of $1.5 \mu \mathrm{m}$ quantum dash lasers on InP," Applied Physics Letters, 92, 011120 (2008)

[3] F. Lelarge et al, "Effect of p-doping on temperature and dynamic performances of 1550nm InAs/InP quantum dash based lasers", Proc. IPRM-2009, ThB1.6, (2009)

[4] N. Chimot et al, "1550nm directly modulated lasers for $10 \mathrm{~Gb} / \mathrm{s}$ SMF transmission up to $65 \mathrm{~km}$ at $45^{\circ} \mathrm{C}$ with chirp optimized InAs/InP quantum dashes,", Proc. ECOC, Tu.9.D.3, Torino (2010)

[5] S. Joshi et al, "Quantum dash based directly modulated lasers for long-reach access networks", Electronics Letters, Vol. 50 no. 7 (2014)

[6] J. Wang et al, "Small signal analysis for dispersive optical fibre communication systems," Lightwave Technology, Journal of , vol.10, no.1, pp.96,100, (1992)

[7] L. Anet Neto, et al., "Simple Estimation of Fibre Dispersion and Laser Chirp Parameters Using the Downhill Simplex Fitting Algorithm," J. Light Tech. , vol.31, no.2, .334,342, (2013) 